\title{
AUTOPERCEPÇÃO DE UM GRUPO DE CRIANÇAS COM DIAGNÓSTICO DE TDAH: IMPLICAÇÕES EDUCACIONAIS
}

\section{SELF-PERCEPTION OF A GROUP OF CHILDREN COM DIAGNOSIS OF ADHD: EDUCATIONAL IMPLICATIONS}

\author{
Margarette Matesco Rocha ${ }^{1}$ \\ https://orcid.org/0000-0003-0906-6228 \\ Mariana Carolina Batista Ferreira ${ }^{2}$ \\ https://orcid.org/0000-0001-8481-4826
}

RESUMO: As crianças com TDAH, frequentemente, apresentam prejuízos nos desempenhos acadêmicos, sociais e comportamentais. Esses prejuízos podem afetar a sua autopercepção de forma negativa ou produzir uma autopercepção com viés positivo. No Brasil ainda são escassos os estudos com essa temática, sobretudo aqueles que se baseiam no relato da própria da criança. O presente estudo teve por objetivo investigar a autopercepção de um grupo de crianças com TDAH, por meio de instrumento padronizado e do relato das próprias crianças. Participaram nove crianças com diagnóstico de TDAH, estudantes do ensino fundamental, cursando entre o $2^{\circ}$ e o 5 ㅇ ano e com idade variando de 7 a 12 anos. Os dados quantitativos e qualitativos mostraram baixa pontuação nos domínios de conduta comportamental e desempenho escolar. O levantamento e a discussão de algumas questões relacionadas à autopercepção das crianças com TDAH poderão contribuir para a condução de intervenções mais efetivas com essas crianças.

PALAVRAS-CHAVE: TDAH, autopercepção, ensino fundamental

ABSTRACT: Children with ADHD often have impairments in academic, social, and behavioral performance. These impairments may affect their self-perception in a negative way or produce a self-perceived positive bias. In Brazil the studies with this theme are still scarce, especially those based on the child's own report. The present study aimed to investigate the self-perception of a group of children with ADHD, by means of a standardized instrument and child's own report. Nine

\footnotetext{
${ }^{1}$ Doutora em Educação Especial, docente da Universidade Estadual do Oeste do Paraná, Francisco Beltrão - Paraná - Brasil. e-mail: margarettematesco@gmail.com

${ }^{2}$ Mestranda do Programa de Pós-Graduação em Análise do Comportamento da Universidade Estadual de Londrina - Londrina - Paraná - Brasil. e-mail: maribatistaferreira@gmail.com
}

Rev. Fac. Educ. (Univ. do Estado de Mato Grosso), Vol. 30, Ano 16, № 2, p. 171-191, jul./dez., 2018 (Epub Ahead of Print 15. abr., 2018) 
children with a diagnosis of ADHD participated, elementary school students, enrolled in the study from the 2 nd to the 5 th year and aged between 7 and 12 years. Quantitative data and the reports showed low scores in behavioral and school performance domains. The survey and discussion of some issues related to the self-perception of children with ADHD may contribute to the conduction of more effective interventions with these children.

KEYWORDS: ADHD; self-perception, elementary school

\section{Introdução}

O Transtorno do Déficit de Atenção e Hiperatividade (TDAH) caracteriza-se pela presença de comportamentos de desatenção, hiperatividade e impulsividade e atinge cerca de 3 a $5 \%$ das crianças em idade escolar (AMERICAN PSYCHIATRIC ASSOCIATION - DSM-V, 2014).

De forma resumida, são crianças que não conseguem focar a atenção, isto é, frente a um conjunto de estímulos aos quais são expostos, não conseguem selecionar o que é relevante e o que deve ser ignorado e, em consequência, seu processo de aprendizagem, acadêmico ou social, é prejudicado (HÜBNER; MARINOTTI, 2000). Considerando o modelo comportamental de autocontrole, supõe-se que o comportamento dessas crianças é afetado, principalmente, por consequências imediatas e que consequências atrasadas têm sua função reduzida, caracterizando o conjunto de comportamentos de impulsividade/hiperatividade observados em indivíduos com TDAH (HOERGER; MACE, 2006; NEEF et al, 2005).

O TDAH talvez seja, atualmente, o transtorno mais discutido e controverso na literatura, com críticas direcionadas ao excessivo número de diagnósticos e aumento proporcional da comercialização do medicamento metilfenidato, que no Brasil aumentou em aproximadamente $775,53 \%$, entre 2003 e 2012 (BARROS, 2014). Adicionalmente, as causas ainda são incertas, havendo aqueles que defendem ser um transtorno de base neurobiológica e genética (COUTO; MELO-JUNIOR; GOMES, 2010), outros que criticam ou refutam a base neurobiológica, afirmando ser uma questão social (SIGNOR, 2013) e, por último, os que questionam a existência do TDAH (VIÉGAS; OLIVEIRA, 2014).

Sobre essa questão, Santos (2015) afirma que há de um lado uma corrente que desconsidera os fatores socioambientais, familiares e educacionais, atribuindo à criança a culpa pelo fracasso escolar, rotulando-as como incapaz ou problemática. Por outro lado, há uma corrente que condena toda forma

Rev. Fac. Educ. (Univ. do Estado de Mato Grosso), Vol. 30, Ano 16, № 2, p. 171-191, jul./dez., 2018 (Epub Ahead of Print 15. abr., 2018) 
de diagnóstico e constituição biológica do indivíduo, considerando apenas as questões sociais e educacionais e, negando assim a possibilidade de uma intervenção médica àquele que pode ter, por esta via, avanços e superações de suas dificuldades.

Essa dissociação em nada contribui para o entendimento de que o TDAH é transtorno multifatorial, não tendo, portanto, uma relação causal unidirecional. Nessa perspectiva é necessário considerar todos os determinantes (sociais, biológicos e pessoais) para o diagnóstico e intervenção. A identificação destas variáveis contribui para desfazer rótulos prévios que frequentemente acompanham as crianças e que não favorecem o engajamento em novas contingências e o desenvolvimento de novos padrões comportamentais (SANTOS; VASCONCELOS, 2010).

Além disso, permite desconsiderar o TDAH como fator causal para o desempenho da criança, sem discutir questões como: as circunstâncias familiares, as deficiências da escola e do processo didático-pedagógico. Assim, para Santos (2015) é necessário o entendimento dos vários aspectos envolvidos na aquisição e manutenção dos comportamentos típicos do transtorno e as prováveis consequências para a própria criança, seus familiares, professores e sociedade em geral.

Dentre as diversas consequências do TDAH para a criança, estudos apontam os prejuízos acadêmicos, com $20 \%$ delas apresentando dificuldade de aprendizagem (BARRY; LYMAN; KLINGER, 2002; SELL-SALAZAR, 2003), com três vezes mais chances de repetirem ou serem suspensas e oito vezes mais chances de serem expulsas da escola, quando comparadas às crianças sem o transtorno (BARKLEY et al., 1990). Essas crianças são descritas como menos envolvidas com as tarefas escolares em comparação aos demais alunos, apresentando mais dificuldades para manter-se na tarefa, seguir as instruções dadas e completar as tarefas dentro da sua capacidade e do padrão esperado (BARKLEY et. al., 1990).

No caso das interações sociais, Barkley (1998) atesta que cerca de $50 \%$ a $60 \%$ das crianças com TDAH experienciam alguma forma de rejeição social pelos colegas, frequentemente, em função da agitação motora e do brincar "desajeitado" que dificulta a sua aceitação pelas crianças sem o transtorno. Ainda segundo Barkley (2002), ao serem socialmente rejeitadas na infância, essas crianças apresentam taxas mais altas de fracasso e desistência escolar, infrações delinquentes, sentimentos de solidão e baixa autoestima.

Para Molina e Maglio (2013) esses prejuízos há muito tempo são relacionados à percepção negativa que as crianças têm de si mesmas, sendo

Rev. Fac. Educ. (Univ. do Estado de Mato Grosso), Vol. 30, Ano 16, № 2, p. 171-191, jul./dez., 2018 (Epub Ahead of Print 15. abr., 2018) 
motivo de preocupação para pais e professores. Porém, deve-se entender que embora as pesquisas sobre autoestima e desempenho acadêmico demonstram comprovada correlação, não é possível afirmar a existência de uma relação causal entre ambas, mas sim a verificação da simultaneidade de ocorrência da baixa estima e do desempenho acadêmico deficiente (PALACIOS; HIDALGO, 1995, apud TONELOTTO; GONÇALVES, 2002).

Nos últimos anos, apesar do aumento de estudos empíricos sobre a autopercepção das crianças com TDAH, os resultados ainda são inconclusivos, com alguns estudos mostrando que elas apresentam viés positivo, ou seja, tendência de avaliar-se mais positivamente ou superestimar suas competências acadêmicas, sociais, emocionais e motoras (HOZA et. al., 2004; MOLINA, 2013), e outros apontando uma tendência de apresentar autopercepção mais negativa do que as crianças sem o transtorno (SOUZA et. al., 2001, TONELOTTO; GONÇALVES, 2002).

No Brasil, embora escassos os estudos que tratam da temática, os dados convergem com aqueles estudos que mostram que a criança com TDAH apresentam autopercepção mais negativa quando comparadas a outros grupos ou quando são avaliadas por pais, professores e pares. $O$ estudo de Tonelotto e Gonçalves (2002), entrevistou 127 crianças, com idade entre 6 e 9 anos, distribuídas em dois grupos, sendo um composto por crianças que apresentavam problemas de atenção e outro no qual isso não ocorria. Os resultados mostraram que as crianças com problemas de atenção, quando comparadas ao outro grupo, apresentavam percepção mais negativa de seu desempenho no contexto da sala de aula, percebiam os professores como menos simpáticos para com elas e eram mais citadas por seus colegas como rejeitadas e, na mesma proporção, menos citadas quando a questão era a aceitação.

Da mesma forma, o estudo realizado por Capelatto et al. (2014) comparou grupos de crianças de 8 a 13 anos de idade, sendo um com diagnóstico de TDAH e outro sem o diagnóstico ou problemas de aprendizagem. Os autores identificaram que as crianças com TDAH se sentem mais culpadas, acreditam que fazem coisas mais erradas e apresentam autoestima negativa. Para os autores, as dificuldades nas funções de atenção e executivas afetam negativamente as performances nos trabalhos da escola e tarefas diárias, que por sua vez, podem impactar o desenvolvimento da autoestima e causar mais sentimento de culpa.

Ainda na América Latina, o estudo feito por Molina e Maglio (2013) com crianças argentinas de 7 a 13 anos, mostrou a mesma tendência dos estudos brasileiros, ao comparar um grupo de crianças com TDAH a outro 
que recebia atendimento psicológico, mas que não tinha esse diagnóstico. $A$ autopercepção mais negativa foi relatada por crianças com TDAH quando da avaliação da sua competência acadêmica, aceitação social, comportamento e autoestima global. Essas mesmas crianças apresentaram ainda viés positivo, quando comparadas à percepção dos pais, nos domínios de competência acadêmica, social e de comportamento.

Considerando o conjunto de dados, observa-se que, apesar de escassos e controversos, a avaliação da autopercepção apresentada por crianças com TDAH constitue uma importante variável para o seu desenvolvimento, podendo subsidiar a análise e (re)construção de práticas no processo de ensino-aprendizagem e de socialização da criança, influenciando a postura de profissionais da educação, dos pais e de outros envolvidos com a criança.

Assim, devido à escassez de estudos brasileiros sobre essa temática e a importância da autopercepção para o desempenho acadêmico e social da criança, o presente estudo teve por objetivo investigar a autopercepção de um grupo de crianças com TDAH, incluindo, além da avaliação por meio de instrumento padronizado, o relato da própria criança.

\section{Método}

Participaram dessa pesquisa 9 crianças com diagnóstico de TDAH, sendo 5 meninos e 4 meninas, cursando os anos iniciais do Ensino Fundamental, com idade entre 7 e 12 anos. A seleção dos participantes foi realizada a partir de uma lista, disponibilizada pela escola. Os critérios para participação foram: a) ter o diagnóstico de TDAH e, b) estar cursando os anos iniciais do Ensino Fundamental (2ㅇ a 5을 ano). A Tabela 1 apresenta as características dos participantes.

Tabela 1- Caracterização dos participantes

\begin{tabular}{ccccc}
\hline Participantes & Gênero & Idade & $\begin{array}{c}\text { Ano } \\
\text { Escolar }\end{array}$ & $\begin{array}{c}\text { Histórico de } \\
\text { Reprovação }\end{array}$ \\
\hline P1 & M & 12 anos & 50 & Sim \\
P2 & M & 8 anos & 30 & Não \\
P3 & F & 11 anos & 50 & Sim \\
P4 & M & 8 anos & 30 & Não \\
P5 & F & 11 anos & 50 & Sim
\end{tabular}

Rev. Fac. Educ. (Univ. do Estado de Mato Grosso), Vol. 30, Ano 16, № 2, p. 171-191, jul./dez., 2018 (Epub Ahead of Print 15. abr., 2018) 


\begin{tabular}{ccccc} 
P6 & $M$ & 7 anos & 2o & Não \\
P7 & $M$ & 7 anos & 2ㅇ & Não \\
P8 & $F$ & 10 anos & 3ㅇ & Sim \\
\hline P9 & $F$ & 12 anos & 4 & Sim \\
\hline
\end{tabular}

Fonte: Elaborada por ROCHA, Margarette Matesco; FERREIRA, Mariana Carolina Batista

O presente estudo origina-se do trabalho desenvolvido para a disciplina de Estágio em Pesquisa em Psicologia e atendeu às exigências éticas necessárias. O Termo de Consentimento Livre e Esclarecido (TCLE) foi disponibilizado para a equipe pedagógica e para os pais dos participantes informando a natureza da pesquisa, solicitando autorização para coleta e publicação dos resultados, e assegurando o sigilo das informações. A pesquisa foi realizada em uma Escola da Rede Pública de Ensino, situada em um município de porte médio do estado do Paraná. Foram utilizados três instrumentos para coleta de dados:

1) Entrevista com a coordenadora pedagógica: realizada para fazer o levantamento do número de crianças com o diagnóstico de TDAH na escola, investigar a história escolar e a participação no Atendimento Educacional Especializado (AEE).

2) Escala Perfil de Autopercepção para crianças (EPAC) é uma tradução e adaptação cultural brasileira do The Self-Perception Profile for Children (SPPC; HARTER, 1985) realizada por Campos (2004). A escala avalia a autopercepção de competência de crianças de 8 a 12 anos em vários domínios. É formada por 36 questões divididas em seis subescalas, cada uma contendo 6 questões. As seis subescalas são: a) Competência escolar/acadêmica; b) Aceitação Social; c) Competência Atlética; d) Aparência Física; e) Conduta Comportamental e f) Mais-valia Global. Cada questão é composta por duas afirmações, interligadas com o conectivo "mas" (por exemplo "algumas crianças têm muitos amigos" mas "outras não têm muitos amigos"). Este tipo de formato permite minimizar a influência da tendência para respostas socialmente desejáveis. Em seguida, é solicitado que a criança pense se a afirmação escolhida é pouco verdadeira ou muito verdadeira para ela. A pontuação é feita atribuindo-se os valores 4 , 3,2 ou 1 . Os escores são somados para obter a pontuação global e também para cada subescala.

3) Entrevista semiestruturada em grupo: Elaborada para esse estudo. Constou de cinco questões abertas, com objetivo investigar o conhecimento das crianças acerca do TDAH, da medicação e a sua autopercepção, incluindo 
a autoimagem, os relacionamentos interpessoais, o desempenho escolar a a capacidade de aprendizagem.

Para a execução do procedimento foi agendado um encontro com a diretora e a coordenadora da escola para apresentar os objetivos e a forma de condução do trabalho e da entrevista. Após a entrevista, foi solicita a relação de nomes das crianças que tinham o diagnóstico de TDAH. Foram selecionadas dez crianças que atendiam os critérios de seleção. Posteriormente, foi encaminhamento o termo de consentimento aos pais e/ou responsáveis. Após receber o consentimento de todos os pais, foi agendado o dia para a realização da entrevista em grupo com as crianças. Apenas uma criança foi excluída da amostra por não comparecer assiduamente à escola, incluindo o dia da coleta de dados.

No dia agendado, as crianças dirigiram-se ao refeitório onde foi conduzida a entrevista em grupo, com duração aproximada de 90 minutos. Antes de iniciar a entrevista, foi feita a explicação dos objetos e das atividades que seriam realizadas. A pesquisadora explicou que iriam conversar sobre algumas crianças que apresentavam o diagnóstico de TDAH e gostaria de saber o que elas sabiam sobre isso. Foi esclarecido que caso não quisessem responder às questões, era só dizer "Passo" e que não seriam questionadas por isso.

No primeiro momento, utilizou-se de um desenho com duas crianças que simulava uma situação de pintura em que cada uma "sujava" a camiseta da outra e questionou a cena. Utilizou-se a figura a fim de atenuar os prováveis efeitos aversivos ou constrangedores às crianças ao relatar sobre o TDAH (iniciar a entrevista falando diretamente sobre elas). No segundo momento, foi iniciada a entrevista, com as questões sendo lançadas ao grupo oralmente, sem ser direcionada a nenhuma das crianças especificamente, por exemplo, evitava-se falar nome da criança antes ou após a pergunta. Cada criança podia responder o que e quando quisesse. Esse procedimento permitiu às crianças retomar alguma questão, refazer sua resposta ou simplesmente não responder.

Na semana seguinte, deu-se início à aplicação individual da EPAC, que teve duração de aproximadamente 40 minutos com cada criança. A pesquisadora lia as duas afirmações para a criança e pedia para que ela the dissesse com qual delas se parecia mais e o quanto (de 1 a 4) essa afirmação era verdadeira. Era solicitado, ainda, que a criança verbalizasse um exemplo de situações cotidianas que justificassem a alternativa escolhida. A pesquisadora, então, assinalava a alternativa escolhida pela criança na folha de respostas. Foram feitas cinco visitas à escola para a aplicação da Escala, totalizando seis encontros destinados à coleta de dados. Após a coleta de dados, foram suge-

Rev. Fac. Educ. (Univ. do Estado de Mato Grosso), Vol. 30, Ano 16, № 2, p. 171-191, jul./dez., 2018 (Epub Ahead of Print 15. abr., 2018) 
ridos os encaminhamentos necessários.

Os dados da EPAC foram analisados a partir das instruções presentes no material que validou a escala para o Brasil e, para os dados qualitativos foi utilizado o método de análise de conteúdo, seguindo as etapas sugerida por Campos (2014).

\section{Resultados}

De acordo com os dados obtidos junto à diretora, a escola possui 288 alunos matriculados em ambos os turnos. Desse total, 17 alunos possuem o diagnóstico de TDAH, o que corresponde a $6 \%$ das crianças que frequentam a escola. Dentre os alunos com diagnóstico de TDAH, 10 estudavam no período vespertino e deveriam frequentar o Atendimento Educacional Especializado (AEE) no período matutino, porém, apenas 2 ou 3 participavam regularmente do atendimento. Os outros 7 alunos que frequentavam o $A E E$, no período vespertino, eram assíduos. Segundo a diretora, essa assiduidade era devido a oferta do almoço que possibilitava a permanência da criança, após a aula, na própria escola. Quanto ao índice de reprovação, verificou-se que 55,5\% da amostra já havia passado por situação de reprovação, sendo que três cursavam o 5ㅇ ano, uma o 4ㅇa ano e outra o 3ㅇano.

O Gráfico 1 apresenta total de pontuação obtida pelos participantes na EPAC. Na somatória padrão dos itens da escala, a pontuação máxima é 144, a mínima é 36 , com a média ficando em torno de 72 pontos.

\section{Gráfico 1- Pontuação total obtida pelos participantes na EPAC}

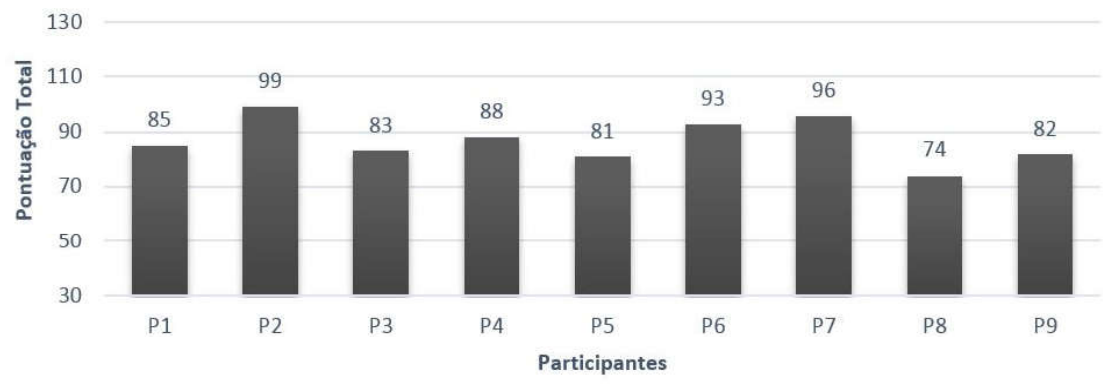

Fonte: Elaborada por ROCHA, Margarette Matesco; FERREIRA, Mariana Carolina Batista

Dados os parâmetros da escala, o Gráfico 1 mostra que todos os 
participantes obtiveram escores superiores a 72 pontos, indicando pontuação acima da média quando comparados à amostra normativa. Os participantes P3, P5, P8 e P9, que obtiveram os menores escores, correspondem a $100 \%$ dos participantes do sexo feminino da amostra. Os participantes P2, P6 e P7, apresentaram mais respostas indicativas de autopercepção mais positiva, atingindo pontuações superiores a 90. De forma geral, observa-se que a maioria das crianças ( $\mathrm{P} 1, \mathrm{P} 3, \mathrm{P} 5, \mathrm{P} 8$ e P9) encontram-se numa posição um pouco superior à média, com pontuações variando entre 74 e 85 .

A pontuação total obtida pelo grupo em cada subescala mostrou que as crianças se avaliaram menos positivamente nas subescalas de Conduta Comportamental (110 pontos) e Competência Escolar (117 pontos) e mais positivamente em Competência Atlética (139 pontos) e Mais-valia geral (146). Nas subescalas Aceitação Social e Aparência Física, as pontuações foram 135 e 134, respectivamente.

Considerando a pontuação individual para cada uma das subescalas, observou-se que os participantes P1, P2, P4 e P6 obtiveram pontuação acima da média em todas as subescalas. Os participantes P7 e P9 apresentaram pontuações inferiores à média em apenas uma das subescalas, sendo que P7 apresentou essa pontuação em Conduta Comportamental e P9 em Competência Escolar. Os demais participantes P3, P5 e P8 apresentaram em mais de uma subescala pontuação inferior à média, sendo que $\mathrm{P} 3$ não alcançou a média nas subescalas Competência Escolar e Conduta Comportamental, P5 em Competência Escolar e Aparência Física e, P8 em Aceitação Social, Aparência Física e Conduta Comportamental. No caso da Mais-valia Global, todos os participantes apresentaram pontuações superiores à média, indicando autopercepção relativamente positiva.

Com relação aos dados obtidos por meio da entrevista, verificou-se que apenas um dos participantes relatou conhecer o diagnóstico de TDAH, afirmando: "Eu sei o que é, eu tenho isso [...] na verdade, me disseram que eu tenho, mas até hoje não sei bem o que é" (P9). Os demais responderam similarmente essa questão com afirmações que demonstraram total desconhecimento: "Eu não faço ideia do que é" (P3).

Apesar da maioria das crianças demonstrarem desconhecimento a respeito da relação entre o diagnóstico e a medicação, elas conseguem descrever "para que serve" a medicação, enfatizando os efeitos sobre diminuição de certos comportamentos considerados inadequados ou aumento de outros mais adequados, principalmente escolares e comportamentais, como pode ser observado nos relatos abaixo:

Rev. Fac. Educ. (Univ. do Estado de Mato Grosso), Vol. 30, Ano 16, № 2, p. 171-191, jul./dez., 2018 (Epub Ahead of Print 15. abr., 2018) 
Eu tomo, é porque eu sou muito elétrico. Eu tomo pra me concentrar, ficar calmo [...] o remédio é para ficar quieto e conseguir prestar atenção na aula, só isso. (P2)

Eu tomo remédio pra prestar atenção e ficar quieto, foi o que me falaram (P4).

Eu não sei direito. Minha mamãe disse que é pra me ajudar na escola, pra conseguir fazer a tarefa. (P7)

Ainda sobre a medicação, duas crianças (P8 e P9) afirmaram não gostar de fazer uso da mesma:

Eu tomo um remédio que não faço questão nenhuma de tomar [...] Minha vó me diz que é pra eu me controlar e pra prestar atenção na aula, e porque eu tenho problema de crescimento [...] minha vó não sabe, mas eu já fingi que tomei o remédio depois joguei fora, eu não gosto de tomar esse remédio. (P8)

Me falaram que eu tenho que tomar um remédio porque eu tenho esse negócio. [...] não sei o que ele faz direito, minha mãe me disse que é pra me ajudar a ficar quieta, me controlar e ir bem na escola [...] não gosto de tomar, é ruim [...] eu queria jogar fora, fingir que tomei, mas minha mãe fica em cima, cuidando, não dá pra segurar e depois jogar fora, ela confere. (P9)

A respeito dos benefícios da medicação, apenas duas crianças enfatizaram esse aspecto, destacando os efeitos sobre a atenção/concentração:

Com o remédio melhorou um pouco, eu até consigo me controlar, mas é que eu era muito elétrico, não conseguia me concentrar, fazer as coisas [...] (P2)

Hoje, com o remédio eu consigo prestar mais atenção na aula, saber as respostas, mas antes não [...] (P4)

Sobre a avaliação do desempenho acadêmico ou da capacidade de aprendizagem, algumas crianças afirmaram que apresentam dificuldades, necessitando de mais tempo para concluir as atividades. Porém, elas reconhecem que quando recebem ajuda conseguem realizar todas as atividades propostas.

Eu sou um pouco diferente das outras crianças, mas não burro. Tenho mais dificuldade, preciso de ajuda. (P4)

Eu consigo fazer meus trabalhos e tarefas, mas preciso de ajuda e tenho muita dificuldade para prestar atenção e sou muito lenta, às vezes acabo levando bronca por isso [...] (P5) 
Eu tenho um pouquinho de dificuldade, mas minha mamãe me ajuda [...] eu tenho dificuldade, mas eu sou inteligente, minha mãe sempre diz que eu sou e eu vou bem nas tarefas e nos trabalhos, eu demoro um pouco, as vezes preciso de ajuda com as respostas, mas eu me saio bem. (P7)

Por outro lado, três participantes não se reconhecem como "inteligentes", descrevendo as dificuldades enfrentadas para a aprendizagem dos conteúdos e para a realização das atividades em sala de aula.

[...] ah, eu não acho que sou inteligente como as outras crianças, eu tenho muita dificuldade. (P4)

Eu sou burra, eu não tenho nada de inteligente como as outras crianças. Eu não consigo fazer minha tarefa, não entendo nada, não sei por que a gente tem que estudar [...] Minha mãe fala que eu tenho dificuldade metal [...] eu tenho dificuldade pra fazer tarefa, pra saber a resposta na prova, sou lenta, 'vish'"' (sic). (P8) Eu não sei ler até hoje direito [...] eu não me acho inteligente, eu não consigo fazer a tarefa, não sei ler direito, já repeti um monte de vezes. Tudo o que eu não sou é inteligente [...] ah, eu demoro pra fazer a tarefa, sou muito lenta, não consigo ler e entender os exercícios, preciso de ajuda, não consigo me lembrar de muita coisa, mas o que me irrita mais é que eu não sei ler direito ainda, isso é muito ruim. (P9)

Os dados referentes à autoimagem, englobou respostas relativas a aparência física e também comportamentais. No tocante à aparência física, com exceção dos participantes P1 e P2, os demais afirmaram não gostar de estar acima do peso (P3, P4, P8), da cor ou jeito do cabelo (P6 e P9) e da estatura (P7). Ainda nessa questão, com exceção de $\mathrm{P} 1, \mathrm{P} 7$ e $\mathrm{P} 6$, os demais participantes acrescentaram aspectos comportamentais, sendo unânimes em afirmar que gostariam de brigar menos, falar menos durante as aulas e se concentrar mais na escola para levar menos bronca.

Os outros dizem que eu sou muito bagunceiro [...] o meu problema é que eu não consigo ficar quieto, eu acho que sou desobediente, as pessoas sempre me dizem isso. Com o remédio melhorou um pouco, eu até consigo me controlar, mas é que eu era muito elétrico, não conseguia me concentrar, fazer as coisas, se eu pudesse eu mudava mais isso, é só isso que me incomoda, o resto não [...] agora eu sou mais feliz do jeito que eu tô, só que eu queria mudar mais, ficar mais quieto e mais parado, não levar 
tanta bronca $[\ldots](P 2)$

Não me acho muito bonita, queria ser diferente, queria ser bonita, mudar meu cabelo, meu rosto [...] tem hora que eu me comporto bem, tem hora que não [...] eu faço coisa que não tá certa, eu sei. Às vezes, eu brigo em casa se me dão muita bronca. Eu falo bastante na sala [...] é difícil prestar atenção na aula, no que as pessoas dizem [...] eu queria mudar, melhorar meu comportamento e minha aparência [...] eu sou briguenta e falo demais, eu mudaria. (P5)

Eu queria ser diferente, queria parar de brigar, queria saber me comportar, mas eles me xingam aí não aguento, me dá muita raiva, tenho vontade de quebrar a cara deles. Uma vez um menino mexeu comigo e eu bati tanto nele [...] eu sei que faço muita coisa errada, que não paro quieta, mas não é tudo que faço que tá errado [...] elas não me deixam brincar, eu sou sozinha. (P8)

Os relatos dos participantes sobre as interações sociais demonstraram que a maioria deles apresentavam dificuldades para realização das atividades escolares em grupos e para entrar nas brincadeiras. As verbalizações de P2 e P3 exemplificam essas dificuldades: "eles (os amigos da escola) nem gostam de fazer trabalho comigo, acho que é porque eu tenho dificuldade" (P2); "eles (amigos da escola) vivem me xingando, na sala na hora do trabalho, não querem fazer trabalho comigo porque eu demoro" (P3).

Os participantes $\mathrm{P} 2$ e $\mathrm{P} 9$, relataram dificuldades para fazer amigos fora do ambiente escolar, implicando em um número restrito de amigos e em isolamento social.

Eu nunca tive muitos amigos, acho muito difícil fazer amigos [...] demorou pra eu ter amigo, fiz no ano passado duas amigas, gostava muito delas, mas elas passaram de ano. (P9)

Eu acho muito difícil fazer amigos, eu não tenho quase amigos, só duas amigas. Em casa eu sou sozinha, não tenho com quem brincar [...] eu queria ter amigos, é difícil ficar sozinha [...] (P3)

Ainda relacionado aos amigos, os participantes relataram as recusas dos amigos quando querem brincar juntos, o desejo de terem mais amigos e de serem aceitos.

Eu tenho amigos, converso com eles, às vezes brinco [...] é que eu acabo ficando mais sozinho mesmo, não sou de ir atrás de 
ninguém, sei que gostam de mim quando as pessoas me convidam para estar junto. (P1)

Eu acho que não tenho dificuldades para fazer amigos, eu tenho amigos, aqui na escola, onde eu treino, eu gosto de estar com eles. Só é ruim quando os outros na escola vão brincar e não me deixam brincar junto [...] eu queria que as pessoas gostassem mais de mim. (P2)

Não acho difícil fazer amigos [...] eu tenho amigos, pra mim tá bom, mas queria ter mais [...] brinco bastante na escola com meus amigos[...] eu acho que queria ter mais amigos e que as pessoas gostassem mais de mim. (P4)

Eu só tinha uma amiga, mas ela saiu, eles xingavam ela e sempre eu defendia ela [...] tiravam sarro dela e da minha cara [...] só levo bronca, de todos [...] sou sozinha, até peço pra brincar, mas eles não deixam, dizem que sou chata [...] (P8)

Quanto às interações sociais com os adultos, observou-se que as mesmas também são permeadas por mais interações aversivas do que positivas, com a maioria das crianças relatando serem alvos de broncas e xingamentos.

Já tomei muito bronca porque não consigo prestar atenção, hoje eu aprendi a ignorar. Eu fico quieto, deixo pra lá, ficava mais triste, agora melhorou [...] se tomo bronca por coisa que fiz de errado eu aceito, mas se não, eu nem me importo [...] (P1) Se minha mãe briga comigo atoa eu brigo com ela [...] bronca, já tô acostumada com bronca, eu levo por qualquer coisa. (P3) Meu pai, às vezes, me xinga e dá um pouquinho de bronca [...] levo bronca na escola da professora, mas já nem ligo. [...] (P4) Minha mãe diz que vai me pôr no orfanato [...]. Podia mesmo, ela nem mora comigo, me deixou com minha avó [...] às vezes ela faz carinho, brinca comigo, faz 'cosquinha', queria que fosse sempre assim [...] se minha mãe e minha vó soubessem o tanto que gosto delas, elas não faziam isso comigo. (P9)

Somente P6 e P7 afirmaram ter relacionamentos com pais e professores livres de "bronca" ou brigas, caracterizando um relacionamento mais positivo.

Não levo bronca da professora, eu faço minhas tarefas, eu só tenho dificuldade [...] ela \{professora\} fala comigo as vezes, é 
porque eu tô demorando, mas ela não briga" (P6)

Minha mamãe e meu papai não brigam comigo, a tia da escola

\section{Discussão}

A partir dos dados obtidos junto à direção da escola, observou-se que o número de criança com o diagnóstico de TDAH (6\%) nessa escola era superior ao estimado mundialmente (entre 3\% e 5\%), porém corresponde a estimativa encontrada no Brasil que gira em torno de 5,8\% (POLANCZYK, 2008). No que concerne ao índice de reprovação, cinco crianças têm pelo menos uma história de reprovação escolar. Isso fornece evidências que crianças com TDAH tendem a ter mais fracassos na escola (BARRY; LYMAN; KLINGER, 2002; SELL-SALAZAR, 2003), com históricos de reprovação no decorrer da sua vida escolar (BARKLEY et al., 1990).

Esse histórico da vida escolar juntamente com o fato de serem consideradas mais lentas para a realização das atividades escolares, parece de fato afetar de forma negativa a autopercepção dessas crianças quanto a sua competência acadêmica, refletida na baixa pontuação obtida pelo grupo. Apesar disso, ao longo da entrevista, as crianças reconhecem que devido às suas dificuldades, elas necessitam da ajuda de outros para conseguir atender às demandas acadêmicas. Esses dados reforçam as evidências que crianças com TDAH, apesar das dificuldades escolares (BARKLEY et al., 1990), podem responder de forma satisfatória às demandas escolares quando são estabelecidas as condições adequadas e, consequentemente, com possibilidade de terem uma autopercepção mais positiva.

Comparativamente às outras subescalas, a de Conduta Comportamental foi a que obteve a menor pontuação, com os relatos demonstrando maior índice de insatisfação e, consecutivamente, mais desejo de mudanças. Para Barber, Grubbs e Cottrell (2005) uma menor pontuação alcançada pelas crianças nessa subescala faz sentido quando se considera que são esses comportamentos problemáticos que chamam a atenção de forma negativa de professores, pais e pares, ocasionando broncas e/ou afastamentos.

Por outro lado, vale destacar que esses comportamentos, tidos como problemáticos, podem ter impacto negativo para a aceitação social, funcionando como círculo vicioso, no qual a emissão de comportamentos hostis aumenta a rejeição dos amigos e a rejeição contribui para a manutenção ou exacerbação desses comportamentos, como relatado por alguns participantes. Essa observação faz necessário, visto que no caso da Aceitação Social, apesar 
da maioria apresentar pontuação acima da média, o relato de sete dos nove participantes mostrou que além de terem poucos amigos, eles também não conseguem estabelecer amizades e lidam com relações interpessoais conflituosas, tais como impedimentos para brincar junto com outras crianças e constantes broncas recebidas dos adultos (pais e professores).

No caso dos relatos sobre a relação com os professores, Benczik (2000) sugere que não é raro essa relação ser atravessada por uma hostilidade que pode ser intensa. O mesmo foi observado na relação com os pais, com a maioria das crianças relatando muitas broncas no ambiente familiar. Essa forma de relacionamento se por um lado parece denunciar os sentimentos que os comportamentos das crianças com TDAH podem, frequentemente, despertar nos pais e professores, por outro, podem ter reflexos negativos para a autopercepção delas e para os seus relacionamentos interpessoais.

Contrariamente, a importância do apoio familiar fica evidente quando se observa, pelos relatos dos participantes P6 e P7, que ele favorece o desenvolvimento da criança, melhorando a sua autopercepção e os desempenhos acadêmicos e sociais. Acerca disso, Rocha e Del Prette (2010) afirmam que a família tem um papel essencial no desenvolvimento e autoconfiança da criança com TDAH, conferindo importância às estratégias de intervenção que auxiliam os pais a lidarem com os seus filhos de forma afetiva e efetiva.

Os resultados obtidos na subescala Mais-valia Geral e na pontuação global mostram que todas as crianças obtiveram pontuações superiores à média, apontando não haver percepção discrepante (muito baixo ou muito acima) quando comparadas à amostra normativa. Esse achado segue a mesma tendência de estudos que fizeram comparações diretas entre crianças com e sem o diagnóstico (RIZZO; STEINHAUSEN; DRECHSLER, 2010), sendo, entretanto, verificado uma discrepância entre a resposta da criança com TDAH nos testes e o seu desempenho real. A existência dessa discrepância pode contribuir para diminuir a consciência das crianças que os seus comportamentos negativos podem gerar conflitos interpessoais (JIA; JIANG; MIKAMI, 2016) e levá-las a ter limitações para ajustar os seus comportamentos aos feedbacks recebidos (McQUADE et al., 2011).

Um outro dado do presente estudo apontou que as crianças com mais idade apresentaram pontuações e verbalizações indicativas de autopercepção mais negativa. Para Hoza et al. (2010) essa diferença deve-se ao aumento da depressão dessas crianças, ocasionada pelas repetidas histórias de fracasso no decorrer dos anos escolares. Esse decréscimo na autopercepção positiva, portanto, alerta para a necessidade de um trabalho de intervenção precoce

Rev. Fac. Educ. (Univ. do Estado de Mato Grosso), Vol. 30, Ano 16, № 2, p. 171-191, jul./dez., 2018 (Epub Ahead of Print 15. abr., 2018) 
com essas crianças, na escola e no ambiente familiar, a fim de minimizar esses efeitos (SCHOLTENS; RYDELL; WALLENTIN, 2013).

As meninas, embora em menor número na amostra, apresentaram pontuações gerais mais negativas que os meninos. Da mesma forma, o estudo de Barber, Grubbs e Cottrell (2005), utilizando a mesma escala desse estudo, verificou que as meninas com TDAH apresentaram escores mais baixos que os meninos na escala geral e em cinco das seis subescalas. Especificamente na subescala Aparência Física, o estudo de Hoza et al. (2004), também mostrou que meninas apresentam pontuações mais baixas e são mais enfáticas quanto ao desejo de mudança na aparência. Uma provável explicação é o fato das meninas sofrerem mais cobranças da sociedade no que diz respeito à aparência física ou serem ensinadas a admirar um padrão de beleza veiculado pela mídia e imposto como parâmetro estético (RIBEIRO; ILDEBRANDO; PLONER, 2009).

$A$ respeito do conhecimento da criança sobre o diagnóstico e o uso do metifenidato, observou-se que nenhuma delas sabia o que era o TDAH, entretanto, relataram acreditar que o mesmo provoca dificuldades, demandando esforços coletivos (amigos, familiares e escola) para que consigam acompanhar as atividades escolares. Quanto à medicação, as descrições das crianças enfatizaram os motivos pelos quais faziam o uso, pautadas em avaliações de seus comportamentos, geralmente, reflexo de descrições de seus pais e professores.

Adicionalmente, apenas dois participantes (P2 e P6) mencionaram benefícios com o uso da medicação para os sintomas do TDAH (inquietação e atenção), porém sem efeitos sobre as interações sociais e comportamentais. Esse dado é consistente com a literatura sugerindo que a medicação, apesar da ampla eficácia para a melhora nos sintomas clássicos do TDAH, não elimina todos os aspectos disfuncionais tipicamente associados ao transtorno, persistindo as habilidades sociais deficitárias, pouca motivação na escola, desempenho acadêmico relativamente baixo e outras complicações (BARKLEY, 2002; KLEIN et al., 2004).

De qualquer forma, essa melhora mais acentuada somente nos sintomas do TDAH evidenciam a necessidade de um tratamento multimodal para auxiliar essas crianças (MTA, 1999), visto que o uso exclusivo do tratamento medicamentoso, pode não produzir melhoras em todos os aspectos. Além disso, favorece o entendimento que são as condições ambientais que favorecem o aparecimento das formas mais graves do transtorno. Por exemplo, as dificuldades escolares podem estar relacionadas a déficits na área de habilidades de estudo, então, sanar as dificuldades orgânicas não seria suficiente para sanar também essas dificuldades. 
Por fim, os dados desse estudo apontaram para a importância da comunidade verbal na construção da autopercepção mais positiva ou negativa dessas crianças, com os relatos retratando, na maioria das vezes, que as descrições avaliativas dos desempenhos feitas por pais e professores serão reproduzidas pelas crianças e, mais importante, afetam a forma como elas avaliam os seus próprios desempenhos.

\section{Considerações finais}

A escolarização da criança com TDAH ainda constitui um grande desafio, visto que além das dificuldades em responder às demandas acadêmicas em termos de aprendizagem, o padrão de interações sociais, com os colegas e os professores, também impõe obstáculos para a participação efetiva em todas as atividades do ambiente escolar.

Esses desafios contribuem para uma autopercepção muitas vezes negativas dessas crianças, sendo contrabalanceada somente quando as pessoas significativas ao seu redor as ajudam a se reconhecerem como pessoas de possibilidades e não com limitações. Isso confere importância às interações estabelecidas com essas crianças e fornece evidências da responsabilidade de todos os envolvidos na busca de uma autopercepção mais positiva e, como consequência, uma história de vida também mais positiva.

Além disso, o reconhecimento dos efeitos ou do papel das interações sobre a autopercepção das crianças, sinalizam a necessidade de modificar a concepção que expressa um determinismo absoluto e linear entre TDAH e autopercepção. Em termos práticos, significa que as proposições de intervenções educacionais, precisam contemplar essas variáveis para diminuir ou minimizar os problemas enfrentados por essas crianças. Obviamente que outras questões referentes à relação entre TDAH e a autopercepção ainda precisam de mais investigações, visto serem os estudos sobre essa temática ainda recentes, no entanto, a importância de entender esse aspecto do comportamento da criança com TDAH e seus determinantes não pode ser descartado.

O pequeno número de participantes da amostra, o fato da seleção ter sido feita por conveniência e a ausência de grupos (de informantes ou de outras crianças sem o diagnóstico) para comparação, impõem restrições quanto a generalização dos dados. No entanto, os dados obtidos por meio dos relatos podem servir como um ponto de partida para novas pesquisas que busquem conhecer mais sobre essas crianças e o impacto do TDAH em suas vidas. Além disso, demonstram a necessidade de ações voltadas para o reconhecimento e

Rev. Fac. Educ. (Univ. do Estado de Mato Grosso), Vol. 30, Ano 16, № 2, p. 171-191, jul./dez., 2018 (Epub Ahead of Print 15. abr., 2018) 
o desenvolvimento das competências dessas crianças, gerando sentimentos

e percepções mais positivas de si mesmas e diminuindo os sentimentos de menos valia que poderá acompanhá-las pela vida, conforme verificado por Boson e Fortaleza (2014).

\section{Referências}

AMERICAN PSYCHIATRIC ASSOCIATION. Manual diagnóstico e estatístico de transtornos mentais (DSM-V). Artmed, 2014.

BARBER, Sara; GRUBBS, Laurie; COTTRELL, Barbara. Self-Perception in Children with Attention Deficit/Hyperactivity Disorder. Journal of Pediatric Nursing, v.20, n.4, jul-ago, 2005, p. 235-245.

BARKLEY, R. A. Attention deficit hyperactivity disorder: a handbook for diagnosis and treatment. New York: Guilford Press, 1998.

- Transtorno de Déficit de Atenção/Hiperatividade (TDAH): guia completo e autorizado para os pais, professores e profissionais da saúde. Porto Alegre: Artmed, 2002.

BARKLEY, Russel A. et al. The adolescent outcome of hyperactive children diagnosed by research criteria: an 8-year prospective follow-up study. Journal of the American Academy of Child \& Adolescent Psychiatry, v. 29, n. 4, jul, 1990, p. 546-557.

BARRY, Tammy DeShazo; LYMAN, Robert D.; KLINGER, Laura Grofer. Hyperactivity disorder: the negative impact of symptom severity on school performance. Journal of School Psychology, v. 40, n. 3, mai-jun, 2002, p. 259-283.

BARROS, Denise Borges. Os usos e sentidos do metilfenidato: experiências entre o tratamento e o aprimoramento da atenção. 2014. 182f. Tese (Doutorado em Saúde Coletiva). Programa de Pós-Graduação em Saúde Coletiva. Universidade do Estado do Rio de Janeiro. UERJ: Rio de Janeiro, 2014.

BENCZIK, E. B. P. Transtorno do déficit de atenção e hiperatividade: atualização diagnóstica e terapêutica. São Paulo: Casa do Psicólogo, 2000.

BOSON, lane Ferreira;; FORTALEZA, Sandra Maria. As consequências da falta de conhecimento acerca do transtorno do déficit de atenção e hiperatividade na vida do indivíduo. Revista FACID: Ciência \& Vida, v.10, n.1, mai, 2014. p. 27-36.

CAMPOS, Angela Alfano. Adaptação cultural da Escala Perfil de Auto-Percep- 
ção para

Crianças. 2004. 68f. Dissertação (Mestrado em Psicologia) Universidade Federal do Rio de Janeiro. Rio de Janeiro: IP/UFRJ, 2004.

CAMPOS, Claudinei José Gomes. Método de análise de conteúdo: ferramenta para a análise de dados qualitativos no campo da saúde. Revista Brasileira de Enfermagem, n. 57, v. 5, 2004, p. 611-614.

CAPELATTO, luri Victor et al. Cognitive functions, self-esteem and self-concept of children with attention deficit and hyperactivity disorder. Psicologia: Reflexão e Crítica, n. 27, v. 2, 2014, p. 331-340.

COUTO, Taciana de Souza; MELO-JUNIOR, Mario Ribeiro de; GOMES, Cláudia Roberta de Araújo. Aspectos neurobiológicos do transtorno do déficit de atenção e hiperatividade (TDAH): uma revisão. Ciências \& Cognição, v.15, n.1, abr, 2010, p. 241-251.

JIA, Mary; JIANG, Yuanyuan; MIKAMI, Amori Yee. Positively biased self-perceptions in children with ADHD: unique predictor of future maladjustment. Journal of Abnormal Child Psychology, v.44, jul, 2016, p. 575-586.

HOERGER, Marguerite; MACE, F. Charles. A computerized test of self-control predicts classroom behavior. Journal of Applied Behavior Analysis, v.39, n.2, p.147-159, 2006.

HOZA, Betsy. et al. Self-perceptions of competence in children with ADHD and comparison children. Journal of Consulting and Clinical Psychology, v.72, n.3, jul, 2004, p.382-391.

HOZA, Betsy. et al. Time-dependent changes in positively biased self-perceptions of children with attention-deficit/hyperactivity disorder: a developmental psychopathology perspective. Development and Psychopathology, v.22, n.2, mai, 2010, p.375-390.

HÜBNER, Maria Martha Costa; MARINOTTI, Míriam. Crianças com dificuldades escolares. In: SILVARES, E. F. M. (Org.). Estudos de caso em psicologia clínica comportamental infantil. Campinas: Papirus, 2000, v.2, p. 259-304.

KLEIN, Rachel G. et al. (2004). Design and rationale of controlled study of long-term methylphenidate and multimodal psychosocial treatment in children with $A D H D$. Journal of the American Academy of Child and Adolescent Psychiatry, v.43, n.7, jul, 2004, p.792-801.

MCQUADE, Julia D. et al. Cognitive Deficits and Positively Biased Self-Percep- 
tions in Children with ADHD. Journal of Abnormal Child Psychology, v. 39, $n$. 2, 2011, p. 307-319.

MOLINA, María Fernanda. Revisão do avanço no estudo das autopercepções das crianças com Transtorno de Déficit de Atenção com Hiperatividade (TDAH). Revista Neuropsicología Latinoamericana, n.5, v.3, 2013, p.16-24.

MOLINA; María Fernanda; MAGLIO, Ana Laura. Características del autoconcepto y el ajuste en las autopercepciones de los niños con transtorno por déficit de atención con hiperactividad de Buenos Aires. Cuadernos de Neuropsicología, v.7, n.2, dez, 2013, p.50-71.

MTA COOPERATIVE GROUP. A 14-month randomized clinical trial of treatment strategies for Attention-Deficit Hyperactivity Disorder (ADHD). Archives of General Psychiatry, v.56, n.12, dez, 1999, p.1073-1086.

NEEF, Nancy A. et al. Behavioral assessment of impulsivity: a comparison of children with and without attention deficit hyperactivity disorder. Journal of Applied Behavior Analysis, v. 38, n. 1, 2005, p. 23-37.

POLANCZYK, Guilherme Vanoni. Estudo da prevalência do transtorno de déficit de atenção/hiperatividade na infância, adolescência e idade adulta. 2008. 160f. Tese. (Doutorado em Medicina). Programa de Pós-Graduação em Ciências Médicas: Psiquiatria. Universidade Federal do Rio Grande do Sul. Porto Alegre: UFRGS, 2008.

RIBEIRO, Larissa Gabrielle de Paula Wehner; ILDELBANDO, Morgana Karoline; PLONER, Katia Simone. A influência da mídia no padrão de beleza das crianças entre 8 e 12 anos: sob a percepção dos pais. 2009. Disponível em: <http:// Siaibib01.univali.br/pdf/Larissa Gabrielle de Paula Wehner Ribeiro e Morgana Karoline Ildebrando.pdf>. Acesso em: 18 dez. 2016.

RIZZO, Patrizia; STEINHAUSEN; Hans-Christoph; DRECHSLER, Renate. Self-perception of self-regulatory skills in children with attention-deficit/hyperactivity disorder aged 8-10 years. ADHD: Attention Deficit and Hyperactivity Disorders, v.2, n.4, dez, 2010. p. 171-183.

ROCHA, Margarette Matesco; DEL PRETTE Zilda Aparecida Pereira. Habilidades sociais educativas para mães de crianças com TDAH e a inclusão escolar. Psicologia Argumento, v. 28, n.60, jan-mar, 2010, p.31-41.

SANTOS, Antonio José Pimentel. Discursos da escola e constituição da subjetividade de estudantes com TDAH. 2015. 111f. Dissertação (Mestrado em Educação). Programa de Pós-Graduação em Educação Faculdade de Educação. Universidade Federal da Bahia. Salvador: UFBA, 2015. 
SANTOS, Letícia de Faria; VASCONCELOS, Laércia Abreu. Transtorno de déficit de atenção e hiperatividade em crianças: uma revisão interdisciplinar. Psicologia: Teoria e Pesquisa. v. 26, n.4, out-dez, 2010, p.717-724.

SCHOLTENS, Sara; RYDELL, Ann-Margret; WALLENTIN, Fan Yang. ADHD symptoms, academic achievement, self-perception of academic competence and future orientation: a longitudinal study. Scandinavian Journal of Psychology, v.54, n.3, jun, 2013, p.205-212.

SELL-SALAZAR, Fernando. Síndrome de hiperactividad y déficit de atención. Revista de Neurologia, v.37, n.4, ago, 2003, p.353-358.

SIGNOR, Rita. Transtorno de déficit de atenção/hiperatividade: uma análise histórica e social. Revista Brasileira de Linguística Aplicada - RBLA, v.13, n.4, nov, 2013, p.1145-1166.

SOUZA, Isabella et al. Comorbidades em crianças e adolescentes com Transtorno do Déficit de Atenção. Arquivos de Neuropsiquiatria, v.59, n.2B, jun, 2001, p.401-406.

TONELOTTO, Josiane Maria de Freitas; GONÇALVES, Vanda Maria Gimenes. Autopercepção de crianças desatentas no ambiente escolar. Revista Estudos de Psicologia (Campinas), n.19, v.3, set-dez, 2002, p.31-41.

VIÉGAS, Lygia de Sousa; OLIVEIRA, Ariane Rocha Felício de. TDAH: conceitos vagos, existência duvidosa. Nuances: estudos sobre educação, v.25, n.1, jan-abr, 2014, p.39-58. 